\title{
Quantitative analysis of the lactic acid and acetaldehyde produced by Streptococcus thermophilus and Lactobacillus bulgaricus strains isolated from traditional Turkish yogurts using HPLC
}

\author{
Y. Gezginc, ${ }^{*}$ F. Topcal, $†$ S. Comertpay, $\ddagger^{1}$ and I. Akyol†‡ \\ *Faculty of Agriculture, Department of Food Engineering, \\ †Research and Development Center for University-Industry Public Relations (USKIM), Microbiology and Microbial Genetics Laboratory, and \\ †Faculty of Agriculture, Department of Agricultural Biotechnology, Kahramanmaraş Sutcu İmam University, 46060/Avsar, Kahramanmaras, Turkey
}

\begin{abstract}
The present study was conducted to evaluate the lactic acid- and acetaldehyde-producing abilities of lactic acid bacterial species isolated from traditionally manufactured Turkish yogurts using HPLC. The lactic acid bacterial species purified from the yogurts were the 2 most widely used species in industrial yogurt production: Streptococcus thermophilus and Lactobacillus bulgaricus. These bacteria have the ability to ferment hexose sugars homofermentatively to generate lactic acid and some carbonyl compounds, such as acetaldehyde through pyruvate metabolism. The levels of the compounds produced during fermentation influence the texture and the flavor of the yogurt and are themselves influenced by the chemical composition of the milk, processing conditions, and the metabolic activity of the starter culture. In the study, morphological, biochemical, and molecular characteristics were employed to identify the bacteria obtained from homemade yogurts produced in different regions of Turkey. A collection of 91 Strep. thermophilus and 35 L. bulgaricus strains were investigated for their lactic acid- and acetaldehyde-formation capabilities in various media such as cow milk, LM17 agar, and aerobic-anaerobic SM17 agar or de Man, Rogosa, and Sharpe agar. The amounts of the metabolites generated by each strain in all conditions were quantified by HPLC. The levels were found to vary depending on the species, the strain, and the growth conditions used. Whereas lactic acid production ranged between 0 and $77.9 \mathrm{mg} / \mathrm{kg}$ for Strep. thermophilus strains, it ranged from 0 to 103.5 $\mathrm{mg} / \mathrm{kg}$ for L. bulgaricus. Correspondingly, the ability to generate acetaldehyde ranged from 0 to $105.9 \mathrm{mg} /$ $\mathrm{kg}$ in Strep. thermophilus and from 0 to $126.9 \mathrm{mg} / \mathrm{kg}$ in L. bulgaricus. Our study constitutes the first attempt
\end{abstract}

Received June 4, 2014.

Accepted September 30, 2014.

${ }^{1}$ Corresponding author: ismailakyol@ksu.edu.tr to determine characteristics of the wild strains isolated from traditional Turkish yogurts, and the approach presented here, which reveals the differences in metabolite production abilities of the wild lactic acid bacteria strains, holds the potential for the selection of the most desirable strains to be used as starters in commercial yogurt manufacture in the future.

Key words: biotechnology, traditional food, acetaldehyde, lactic acid

\section{INTRODUCTION}

Lactic acid bacterial species (LAB) are an industrially important group of bacteria and are used for the production of fermented foods, such as cheese, butter, and yogurt. When LAB ferment milk sugar (lactose), they produce lactic acid and some volatile compounds, which ultimately generate yogurt with its characteristic texture and taste. Yogurt is one of the most popular fermented milk products around the world (Magenis et al., 2006) for its flavor, health benefits, and therapeutic values. It is an excellent source of calcium, and it provides proteins containing all amino acids that are essential to human health. Besides, the vitamins and minerals found in yogurt are bioavailable, thus they can be readily absorbed and used by the body. In addition to the above-mentioned nutritional values, yogurt can contribute to gastrointestinal health and is beneficial for certain conditions including lactose intolerance, diarrheal diseases, and colon cancer (Adolfsson et al., 2004).

The most common LAB species that are used as starter cultures in industrial yogurt production are Streptococcus thermophilus and Lactobacillus bulgaricus (Ginovart et al., 2002). When coexisted in the starter, the 2 strains synergistically alter the physicochemical properties and the combination of aroma compounds in yogurt as compared with the products made using each single strain separately (Georgala et al., 1995). Although both species are able to produce lactic acid, a variety of aromatic compounds, and organic acids, 
which altogether constitute the typical flavor and the texture of yogurt, their productivities differ considerably (Cheng, 2010). Therefore, the levels of the molecules found in the final product change depending on the type and the percentage of the LAB strains present in a starter culture.

As an imperative source of flavor and functionality in numerous fermented food products, lactic acid is also responsible for the refreshing tart flavor of yogurt (Panagiotidis and Tzia, 2001). It is a well-studied metabolite generated from lactose by a chain of enzymatic reactions that occur during fermentation and is a crucial component of yogurt production because it helps the formation of the yogurt gel by reducing the $\mathrm{pH}$ and solubilizing micellar calcium phosphate (Zhang et al., 2011). Its content in yogurt is usually around $0.9 \%$, and it provides the product with a sharp and acidic taste (Cheng, 2010).

Lactic acid has 2 stereoisomers, $\mathrm{D}(-)$ and $\mathrm{L}(+)$, that may be produced via reduction of pyruvate by various lactate dehydrogenases (LDH) grouped as D-LDH and L-LDH depending on the isomer they lead to form. The gene encoding the L-LDH enzyme in Strep. thermophilus was cloned and found to carry at least $60 \%$ similarity with other LAB species, such as Streptococcus mutans, Lactococcus lactis, Lactobacillus casei, and Lactobacillus plantarum, and to contain a promoter-like sequence akin to the Escherichia coli promoter consensus (Ito and Sasaki, 1994). The enzyme was also determined to be coded by the 987-bp-long ldh gene in 2 strains of Strep . thermophilus, CNRZ1066 and LMG18311 (Bolotin et al., 2004). In L. bulgaricus strain 2308, on the other hand, 5 genes were identified to encode $\mathrm{LDH}$, with 3 (ldhD1, LBU0066; ldhD2, LBU0860; ldhD3, LBU1637) encrypting D-LDH, whereas 2 (ldhL1, LBU0059; ldhL2, LBU0084) were used in L-LDH production, despite to their unequal expression levels (Hao et al., 2011). Additionally, it was found that L. bulgaricus strain ND02 had an $l d h$ gene that occupies a 924-bp-long space in its 2,125,753-bp circular DNA (Sun et al., 2011).

Along with lactic acid, acetaldehyde, diacetyl acetoin, acetone, and 2-butanone substantially redound to the typical aroma of yogurt. The characteristic aroma of the product is defined by the amount of acetaldehyde found in it, and acetaldehyde concentration in the range of 23 to $40 \mathrm{mg} / \mathrm{kg}$ is required to consider yogurt as having good flavor (Cheng, 2010).

During yogurt fermentation, acetaldehyde can be produced through pyruvate decarboxylation or amino acid conversion. As for amino acid conversion, threonine can be directly transformed into acetaldehyde by the enzymatic activity of threonine aldolase. In Strep. thermophilus, the only enzyme with threonine aldolase activity is glyA enzyme, also known as serine hydroxy- methyl transferase (SHMT, EC 2.1.2.1.) This enzyme is encoded by the gly $A$ gene in the species, and its overexpression has been reported to significantly increase acetaldehyde formation, whereas threonine aldolase activity is completely obstructed when it is disrupted (Chaves et al., 2002). An identical gene for the enzyme has been detected in 3 strains of Strep. thermophilus: CNRZ1066, LMG18311, and JIM8232 (Bolotin et al., 2004; Delorme et al., 2011). In L. bulgaricus, however, no such gene has yet been identified (Sun et al., 2011).

It was previously shown that the strains in starter cultures could produce distinctly different flavors depending on their origins, and that some wild strains might be functional to produce dairy products with special traits (Ayad et al., 1999). Besides, it has also been demonstrated that the flavor-forming abilities of LAB differ not only among species but also within the strains of the same species (Pastink et al., 2008). Therefore, to obtain a product with the qualities in demand, it is critical to recognize the metabolite formation abilities of strains to be used as starters.

Industrial strains of LAB are commercially available, whereas wild strains of LAB can be obtained from assorted sources, ranging from milk environments to plants, animals, and soil (Ayad et al., 2000). In Turkey, where industrial yogurt production has recently reached more than 1 million tonnes in a year, traditional yogurt has been manufactured in individual households for centuries (Kabak and Dobson, 2011). Nevertheless, the properties of the LAB strains isolated from traditional Turkish yogurts have been poorly studied. The present work focuses on analyzing the lactic acid- and acetaldehyde-formation abilities of Strep. thermophilus and L. bulgaricus strains isolated from traditional Turkish yogurts made in various regions of the country so as to evaluate their potentials to be used as a starter in yogurt industry.

\section{MATERIALS AND METHODS}

\section{Isolation of Bacterial Strains}

A total of 126 strains of Strep. thermophilus and L. bulgaricus were assayed for lactic acid and acetaldehyde production. To isolate the strains from homemade traditional yogurts produced in different parts of Turkey, a modified version of the method described by Kao et al. (2007) was used. In short, the samples were aseptically weighted, homogenized, and centrifuged at $850 \times g$ at $4^{\circ} \mathrm{C}$ for $3 \mathrm{~min}$. The supernatant was transferred to a clean tube and recentrifuged at $17,000 \times g$ at $4^{\circ} \mathrm{Cfor} 30$ s. The supernatant was again transferred and centrifuged at $17,000 \times g$ at $4^{\circ} \mathrm{C}$ for $15 \mathrm{~min}$. The pellet was diluted as 1:10 by using peptone water (Sigma-Aldrich, 
St. Louis, MO). Followed by making a 10-fold serial dilution, $0.1 \mathrm{~mL}$ of each sample was subcultured in triplicate. The samples were inoculated in Petri dishes with de Man, Rogosa, and Sharpe (MRS) agar for $L$. bulgaricus and SM17 agar for Strep. thermophilus, and the dishes were incubated at 37 and $42^{\circ} \mathrm{C}$, respectively.

\section{Identification of Strains}

Morphological and Biochemical Identification. Despite the fact that each bacteria species was expected to grow in their best-suited media predominantly, cell morphology, Gram staining, and catalase-activity properties of the strains were analyzed to approve their identities. After the standard Gram staining method was performed, catalase activity was measured by dropping $20 \mu \mathrm{L}$ of $3 \% \mathrm{H}_{2} \mathrm{O}_{2}$ (Sigma-Aldrich) on gram-positive cells and observing whether any bubble formation has occurred or not. Only the morphologically suitable and gram-positive colonies with no catalase activity were further analyzed.

Molecular Identification. Grown single colonies were checked by species-specific PCR and used the length of the PCR products to verify the species as previously described (Tabasco et al., 2007). Primers within variable regions in the $16 \mathrm{~S}$ rRNA encoding genes of Strep. thermophilus and L. bulgaricus (StF: 5' ACGCTGAAGAGAGGAGCTTG 3', StR: $5^{\prime}$ GCAATTGCCCCTTTCAAATA $3^{\prime}$ and LbF: $5^{\prime}$ TCAAAGATTCCTTCGGGATG $3^{\prime}$, LbR: $5^{\prime}$ TACGCATCATTGCCTTGGTA 3') were purchased from Inontek (Istanbul, Turkey). Polymerase chain reaction was performed in $40 \mu \mathrm{L}$ by using $5 \mathrm{U} / \mu \mathrm{L}$ DNA polymerase (Thermo Scientific, Waltham, MA) and $10 \times$ PCR buffer (Thermo Scientific). A total of 20 pmol of each primer was used, and deoxynucleoside triphosphate (Thermo Scientific) was used at a concentration of $250 \mu M$ each. The amplification condition was as follows: predenaturation at $95^{\circ} \mathrm{C}$ for $5 \mathrm{~min}, 30$ cycles of $94^{\circ} \mathrm{C}$ for $30 \mathrm{~s}, 60^{\circ} \mathrm{C}$ for $20 \mathrm{~s}$ and $72^{\circ} \mathrm{C}$ for $20 \mathrm{~s}$, and a final extension at $72^{\circ} \mathrm{C}$ for $5 \mathrm{~min}$. The products $(5 \mu \mathrm{L}$ plus $1 \mu \mathrm{L}$ of $6 \times$ loading dye) were run on a $2 \%$ agarose gel. Amplicons with 157 bp verified Strep. thermophilus identity, whereas L. bulgaricus was defined with 232-bp PCR band. After molecular identification was completed, the identities of the colonies were confirmed by their visualization under electron microscope.

\section{Growth Conditions}

Once their identities were verified, Strep. thermophilus strains $(\mathrm{n}=91)$ were grown in cow milk or in SM17 prepared by adding 1\% (wt/vol) sucrose to M17 medium (Terzaghi and Sandine, 1975) at $42^{\circ} \mathrm{C}$ under aerobic and anaerobic conditions. Lactobacillus bulgaricus strains $(\mathrm{n}=35)$, on the other hand, were grown in cow milk or in MRS medium (De Man et al., 1960) at $37^{\circ} \mathrm{C}$ under aerobic and anaerobic conditions. Anaerobic conditions were obtained as previously described (Akyol et al., 2009).

\section{Metabolic-End-Products Analysis by HPLC}

The amounts of lactic acid and acetaldehyde present in the growth media where each isolate carried fermentation were analyzed using HPLC [Research and Development Center for University-Industry-Public Relations (USKIM) Kahramanmaras Sutcu Imam University, Turkey] as described by Akyol et al. (2009). Briefly, $1 \mathrm{~mL}$ of overnight cultured medium was centrifuged at $14,000 \times g$ at $4^{\circ} \mathrm{C}$ for $5 \mathrm{~min}$. The supernatant was filtered and placed in a fresh Eppendorf tube. The sample was diluted 1 -fold in $0.5 \%$ meta-phosphoric acid (Sigma-Aldrich), and $20 \mu \mathrm{L}$ of the solution was injected onto the HPLC. Separation was performed on a $150 \times$ 4.6-mm Capcell Pak $5 \mu M$ C18 MG column (Shiseido Co. Ltd., Tokyo, Japan) by using continuous gradient elution with phosphate buffer solution (mobile phase A; Sigma-Aldrich) and acetonitrile (mobile phase B; Sigma-Aldrich) at $30^{\circ} \mathrm{C}$. The total separation time was $5 \mathrm{~min}$, and the gradient was run for 6 min to ensure full separation. Besides, the extension of the HPLC column from 250 to $400 \mathrm{~mm}$ has provided us with a technique that can be used to separate acetaldehyde and L-lactic acid in a single run.

Calibration graphs for absorbances against changing concentrations of the metabolites were drawn to calculate acetaldehyde and lactic acid amounts in samples. Llactic acid, which absorbs the light at $277 \mathrm{~nm}$, was used as the standard for lactic acid; consequently, lactic acid concentrations were represented chiefly by the L-lactic acid produced. Acetaldehyde levels, on the other hand, were detected by the absorbance of the light at $210 \mathrm{~nm}$.

\section{Statistical Analysis}

The ANOVA and differences between means were tested by one-way ANOVA using SPSS software (SPSS Inc., Chicago, IL). The results were considered to be statistically significant when the $P$-value was $\leq 0.001$.

\section{RESULTS}

\section{Isolation and Identification}

A total of 91 strains were identified as Strep. thermophilus thanks to the species-specific PCR that produced 157-bp band, whereas 36 strains were found to 
belong to L. bulgaricus species generating 232-bp PCR band (data not shown). Under electron microscope, shapes of the strains verified the molecular findings (data not shown).

\section{Metabolite Production by Strep. thermophilus Isolates}

The HPLC analyses for Strep. thermophilus strains (shown in Table 1) revealed that in anaerobic SM17, the highest amount of acetaldehyde was produced by BioSt169 $(69.65 \pm 2.2 \mathrm{mg} / \mathrm{kg})$, whereas the lowest was measured for BioSt22 $(0.0 \pm 0.0 \mathrm{mg} / \mathrm{kg})$. In aerobic SM17, however, BioSt164 was the most productive isolate $(99.6 \pm 0.6 \mathrm{mg} / \mathrm{kg})$, whereas BioSt36 was the least productive $(0.1 \pm 0.0 \mathrm{mg} / \mathrm{kg})$. When the isolates were grown in LM17, BioSt164 and BioSt47 generated the highest $(105.9 \pm 8.4 \mathrm{mg} / \mathrm{kg})$ and the lowest $(0.9 \pm$ $0.0 \mathrm{mg} / \mathrm{kg}$ ) amount of acetaldehyde, respectively. As for in milk, the most productive isolate was BioSt47 $(21.1 \pm 0.1 \mathrm{mg} / \mathrm{kg})$ and the least productive strain was BioSt109 $(0.0 \pm 0.0 \mathrm{mg} / \mathrm{kg})$.

Similar to acetaldehyde, lactic acid production also varied depending on the isolates and the culture conditions. In anaerobic SM17, BioSt55 formed the highest amount $(57.7 \pm 0.0)$, whereas BioSt71 produced the lowest $(0.0 \pm 0.0 \mathrm{mg} / \mathrm{kg})$. Under aerobic conditions of SM17, lactic acid was formed by BioSt76 the most $(77.9 \pm 0.0 \mathrm{mg} / \mathrm{kg})$ and by BioSt38 the least $(1.7 \pm 0.2$ $\mathrm{mg} / \mathrm{kg})$. In LM17, maximum amount of acetaldehyde was found in BioSt83 $(63.1 \pm 0.0 \mathrm{mg} / \mathrm{kg})$ and minimum in BioSt118 $(2.6 \pm 0.3 \mathrm{mg} / \mathrm{kg})$. For milk, BioSt83 was the most productive strain $(54.3 \pm 0.0 \mathrm{mg} / \mathrm{kg})$, whereas BioSt30 was the least productive $(0.0 \pm 0.0 \mathrm{mg} / \mathrm{kg})$.

Considering the fact that edible yogurts are made of milk, the amounts of the metabolites produced in milk by the strains of Strep. thermophilus that generated the highest amount of acetaldehyde (BioSt164) and lactic acid (BioSt76) were compared. They were able to produce as low as 1.8 and $0.5 \%$ of acetaldehyde and lactic acid produced in their best conditions, respectively, and the differences were calculated to be statistically significant $(P<0.001)$.

\section{Metabolite Production by L. bulgaricus Isolates}

As presented in Table 2, different isolates of $L$. bulgaricus showed varying metabolite-production abilities in each culture condition. In both anaerobic and aerobic MRS, for instance, the highest amount of acetaldehyde was generated by BioLb130 (77.3 \pm 2.6 and $126.9 \pm 0.2$ $\mathrm{mg} / \mathrm{kg}$, respectively), whereas the lowest was formed by BioLb199 $(0.3 \pm 0.1 \mathrm{mg} / \mathrm{kg})$ under anaerobic and by BioLb198 $(0.7 \pm 0.0 \mathrm{mg} / \mathrm{kg})$ under aerobic conditions.
Among the isolates grown in LM17, however, BioLb152 was the most acetaldehyde-producing strain (78.8 \pm $3.2 \mathrm{mg} / \mathrm{kg}$ ), whereas BioLb180 was the least productive $(0.5 \pm 0.1 \mathrm{mg} / \mathrm{kg})$. As for milk, BioLb181 produced acetaldehyde the most $(58.0 \pm 0.0 \mathrm{mg} / \mathrm{kg})$, and BioLb183 produced it the least $(0.4 \pm 0.1 \mathrm{mg} / \mathrm{kg})$.

Similarly, lactic acid production changed remarkably depending on the isolate and the culture condition it was grown. In MRS, BioLb181 was the most productive isolate $(25.9 \pm 0.2 \mathrm{mg} / \mathrm{kg})$ when oxygen was depleted. BioLb152, on the other hand, was found to be the leastproductive strain $(0.6 \pm 0.1 \mathrm{mg} / \mathrm{kg})$ in the same state. When oxygen was present in MRS, BioLb155 showed the highest $(103.5 \pm 4.1 \mathrm{mg} / \mathrm{kg})$ and BioLb73 showed the lowest $(3.0 \pm 0.2 \mathrm{mg} / \mathrm{kg})$ lactic acid production. In LM17, BioLb73 generated lactic acid the most (95.1 \pm $0.0 \mathrm{mg} / \mathrm{kg}$ ), whereas BioLb185 produced it the least $(1.3 \pm 0.2 \mathrm{mg} / \mathrm{kg})$. Lastly, when milk was used as the growth media, BioLb181 and BioLb98 manufactured the highest $(25.9 \pm 0.1 \mathrm{mg} / \mathrm{kg})$ and the lowest $(0.0 \pm$ $0.0 \mathrm{mg} / \mathrm{kg}$ ) amount of lactic acid, respectively.

A comparison for the metabolites produced in milk and other media was also made for L. bulgaricus, and it was found that the amount of the metabolites produced by L. bulgaricus strains in milk was significantly $(P<0.001)$ lower than the amount generated in their best conditions. Acetaldehyde produced in milk by the most acetaldehyde-productive strain (BioLb130) was only $12.7 \%$ of its highest performance, and lactic acid produced in milk by the most lactic acid-producing strain (BioLb155) was only $0.1 \%$ of what was generated in aerobic MRS.

\section{DISCUSSION}

Bacteria used in starter cultures during the manufacture of yogurt are of great importance because they have the ability to directly influence the nutritional and commercial value of the final product. In the yogurt industry, commercially available strains of 2 microorganisms, Strep. thermophilus and L. bulgaricus, are most commonly used. Although these strains are able to produce the yogurt with desirable properties in a profitable way, some wild strains to be discovered may be superior to them and increase the qualities of the product, decrease the expenses for yogurt production, or produce new types of yogurt with alternative properties. In this study, we aimed to isolate some wild strains of Strep. thermophilus and L. bulgaricus from traditionally made Turkish yogurts to investigate their ability to produce flavor-forming metabolites: acetaldehyde and lactic acid.

In the literature, it has been mentioned that acetaldehyde-producing abilities of the LAB species are rather 
Table 1. Amounts (means \pm SD) of metabolites acetaldehyde and lactic acid produced by 91 strains of Streptococcus thermophilus under various culture conditions

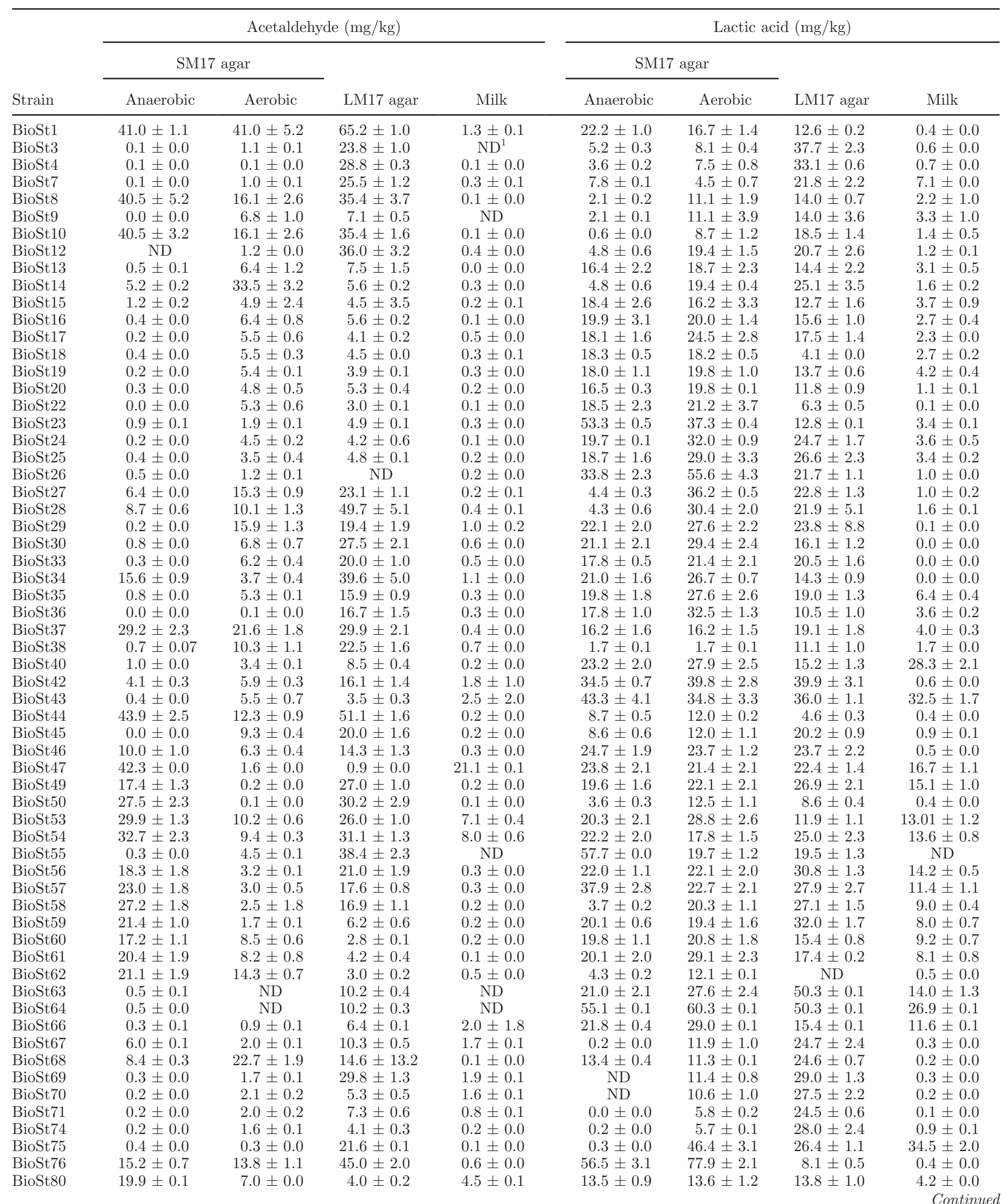


Table 1 (Continued). Amounts (means \pm SD) of metabolites acetaldehyde and lactic acid produced by 91 strains of Streptococcus thermophilus under various culture conditions

\begin{tabular}{|c|c|c|c|c|c|c|c|c|}
\hline \multirow{2}{*}{ Strain } & \multicolumn{4}{|c|}{ Acetaldehyde $(\mathrm{mg} / \mathrm{kg})$} & \multicolumn{4}{|c|}{ Lactic acid (mg/kg) } \\
\hline & \multicolumn{2}{|c|}{ SM17 agar } & LM17 agar & Milk & \multicolumn{2}{|c|}{ SM17 agar } & LM17 agar & Milk \\
\hline BioSt81 & $7.7 \pm 0.7$ & $20.0 \pm 1.0$ & $6.8 \pm 0.6$ & $0.3 \pm 0.0$ & $6.2 \pm 0.0$ & $6.1 \pm 0.6$ & $22.4 \pm 0.4$ & $0.0 \pm 0.0$ \\
\hline BioSt83 & $13.5 \pm 0.2$ & $36.6 \pm 1.0$ & $48.8 \pm 0.8$ & $11.3 \pm 0.4$ & $17.7 \pm 0.2$ & $4.1 \pm 0.0$ & $63.1 \pm 3.0$ & $54.3 \pm 2.8$ \\
\hline BioSt85 & $20.2 \pm 1.7$ & $21.2 \pm 0.3$ & $30.4 \pm 2.3$ & $4.8 \pm 0.3$ & $8.0 \pm 0.3$ & $2.8 \pm 0.0$ & $34.5 \pm 3.1$ & ND \\
\hline BioSt97 & $7.6 \pm 0.5$ & $5.6 \pm 0.4$ & $6.2 \pm 0.5$ & $0.1 \pm 0.0$ & $6.8 \pm 0.4$ & $27.8 \pm 2.4$ & $18.6 \pm 1.2$ & $0.2 \pm 0.0$ \\
\hline BioSt99 & $17.0 \pm 0.7$ & $19.5 \pm 0.4$ & $24.8 \pm 2.2$ & $0.8 \pm 0.0$ & $21.6 \pm 1.8$ & $13.5 \pm 1.0$ & $10.5 \pm 1.1$ & $0.6 \pm 0.1$ \\
\hline BioSt100 & $8.6 \pm 1.4$ & $12.6 \pm 1.8$ & $11.0 \pm 1.6$ & $0.2 \pm 0.0$ & $7.3 \pm 0.4$ & $9.6 \pm 0.4$ & $21.4 \pm 3.9$ & $0.1 \pm 0.0$ \\
\hline BioSt102 & $4.1 \pm 0.6$ & $15.0 \pm 1.3$ & $3.8 \pm 0.2$ & $0.1 \pm 0.0$ & $6.8 \pm 0.5$ & $10.1 \pm 1.8$ & $23.1 \pm 1.8$ & $0.1 \pm 0.0$ \\
\hline BioSt104 & $7.9 \pm 1.8$ & $20.6 \pm 1.8$ & $5.4 \pm 1.6$ & $0.1 \pm 0.0$ & $6.8 \pm 0.9$ & $10.1 \pm 0.7$ & $23.4 \pm 1.6$ & $0.1 \pm 0.0$ \\
\hline BioSt108 & $6.8 \pm 0.5$ & $12.8 \pm 1.2$ & $4.5 \pm 0.3$ & $0.1 \pm 0.0$ & $7.9 \pm 0.6$ & $11.2 \pm 0.9$ & $13.2 \pm 0.4$ & $0.1 \pm 0.0$ \\
\hline BioSt109 & $21.3 \pm 1.5$ & $14.3 \pm 1.1$ & $15.4 \pm 1.1$ & $0.0 \pm 0.0$ & $11.3 \pm 0.0$ & $18.6 \pm 1.2$ & $12.5 \pm 1.1$ & $0.3 \pm 0.0$ \\
\hline BioSt121 & $27.5 \pm 2.0$ & $1.1 \pm 0.1$ & $21.4 \pm 1.2$ & $1.1 \pm 0.0$ & $12.8 \pm 1.2$ & $11.4 \pm 1.1$ & $13.0 \pm 1.0$ & $0.2 \pm 0.0$ \\
\hline BioSt123 & $20.4 \pm 1.8$ & $1.8 \pm 0.1$ & $20.5 \pm 1.4$ & $1.2 \pm 0.1$ & $3.9 \pm 0.2$ & $9.6 \pm 0.4$ & $12.1 \pm 1.1$ & $0.2 \pm 0.0$ \\
\hline BioSt127 & $22.1 \pm 1.0$ & $9.5 \pm 0.6$ & $18.6 \pm 1.4$ & $0.7 \pm 0.0$ & $9.0 \pm 0.6$ & $13.3 \pm 1.0$ & $14.4 \pm 1.0$ & $0.2 \pm 0.0$ \\
\hline BioSt132 & $11.1 \pm 1.1$ & $13.6 \pm 1.1$ & $32.3 \pm 3.3$ & $0.3 \pm 0.0$ & $0.2 \pm 0.0$ & $5.6 \pm 0.4$ & $10.0 \pm 0.7$ & $0.1 \pm 0.0$ \\
\hline BioSt134 & $26.9 \pm 2.5$ & $3.0 \pm 0.3$ & $20.4 \pm 2.0$ & $0.5 \pm 0.0$ & $18.5 \pm 1.3$ & $2.3 \pm 0.2$ & $12.9 \pm 0.8$ & $0.01 \pm 0.0$ \\
\hline BioSt161 & $11.2 \pm 0.8$ & $8.0 \pm 0.2$ & $14.6 \pm 1.3$ & $1.2 \pm 0.1$ & $7.7 \pm 0.5$ & $9.4 \pm 0.7$ & $14.8 \pm 1.1$ & $0.1 \pm 0.0$ \\
\hline BioSt162 & $28.9 \pm 1.4$ & $23.5 \pm 0.1$ & $29.2 \pm 2.8$ & $1.9 \pm 0.1$ & $15.7 \pm 1.3$ & $23.9 \pm 2.1$ & $22.3 \pm 1.7$ & $0.2 \pm 0.0$ \\
\hline BioSt164 & $65.8 \pm 4.9$ & $99.6 \pm 7.9$ & $105.9 \pm 8.4$ & $1.9 \pm 0.1$ & $14.9 \pm 1.2$ & $25.2 \pm 1.5$ & $40.7 \pm 1.9$ & $1.4 \pm 0.0$ \\
\hline BioSt169 & $69.7 \pm 2.2$ & $97.8 \pm 2.1$ & $68.3 \pm 3.7$ & $0.4 \pm 0.0$ & $19.9 \pm 0.7$ & $28.6 \pm 1.7$ & $31.0 \pm 0.6$ & $3.2 \pm 0.4$ \\
\hline BioSt171 & $43.5 \pm 3.5$ & ND & $53.4 \pm 2.1$ & $0.2 \pm 0.0$ & $19.4 \pm 1.7$ & ND & $44.5 \pm 1.0$ & $7.6 \pm 0.6$ \\
\hline BioSt172 & $64.0 \pm 4.5$ & ND & ND & $0.2 \pm 0.0$ & $18.7 \pm 1.1$ & ND & $42.3 \pm 2.2$ & $3.8 \pm 0.0$ \\
\hline BioSt173 & $41.9 \pm 3.9$ & ND & $46.3 \pm 3.0$ & $16.6 \pm 1.4$ & $14.8 \pm 1.3$ & ND & $45.3 \pm 2.9$ & $11.0 \pm 1.1$ \\
\hline
\end{tabular}

${ }^{1} \mathrm{ND}=$ not detectable.

dissimilar despite the fact that they both are capable of generating the metabolite in sufficient amounts to produce yogurt with an acceptable taste (Ozer and Atasoy, 2002). By indicating its dependence on the strain used, the optimum physiological conditions for acetaldehyde production were summarized as $37^{\circ} \mathrm{C}$ at $\mathrm{pH} 4.2$ in heated milk at $65^{\circ} \mathrm{C}$ for $30 \mathrm{~min}$ in Strep. thermophilus (Singh, 1983). Streptococcus thermophilus has been reported to produce acetaldehyde in the range of 1.0 to $13.5 \mathrm{mg} /$ $\mathrm{kg}$, whereas L. bulgaricus has been found to generate it between 1.4 and $77.5 \mathrm{mg} / \mathrm{kg}$ in milk (Routray and Mishra, 2011). Acetaldehyde production has also been shown to be time dependent. It has been demonstrated that both Strep. thermophilus and L. bulgaricus were able to produce the highest amount of acetaldehyde in $115^{\circ} \mathrm{C}$ preheated milk with $\mathrm{pH} 6.2$ to 6.3 at $45^{\circ} \mathrm{C}$ around the 22nd hour of fermentation (Beshkova, et al., 1998). Our measurements revealed an extended range for the acetaldehyde generated by Strep. thermophilus in the same media, where its amount ranged between 0.0 and $21.1 \mathrm{mg} / \mathrm{kg}$. Albeit evidently higher than the amount produced by Strep. thermophilus, acetaldehyde produc- tion by $L$. bulgaricus was found to be lower than what was presented in the literature, remaining between 0.4 and $58.0 \mathrm{mg} / \mathrm{kg}$. Of all the isolates that were scrutinized in terms of their abilities to form acetaldehyde in milk, only 4 were found to generate the metabolite within the acceptable range $(23-40 \mathrm{mg} / \mathrm{kg})$ that is suggested for a well-flavored yogurt (Cheng, 2010). Surprisingly, all 4 strains belonged to L. bulgaricus species, whereas none from Strep. thermophilus was able to reach even the minimum limit.

Streptococcus thermophilus and L. bulgaricus are 2 species of LAB that are capable of producing 2 isomers of lactic acid [i.e., $\mathrm{L}(+)$ and $\mathrm{D}(-)]$. Optimal lactic acid production is known to be strain dependent. However, the best value for Strep. thermophilus was measured in whey permeate at $42^{\circ} \mathrm{C}$ at $\mathrm{pH} 5.8$, whereas for $L$. bulgaricus, it was detected in molasses at $47^{\circ} \mathrm{C}$ (Hofvendahl and Hahn-Hägerdal, 2000). In our study, we used HPLC to evaluate the levels of lactic acid produced by the bacteria. As it was shown previously, HPLC has the potential to separate $\mathrm{D}(-)$ and $\mathrm{L}(+)$ lactic acid and to measure their levels independently (Olieman and de 
Table 2. Amounts (means $\pm \mathrm{SD}$ ) of metabolites acetaldehyde and lactic acid produced by 35 strains of Lactobacillus bulgaricus under various culture conditions

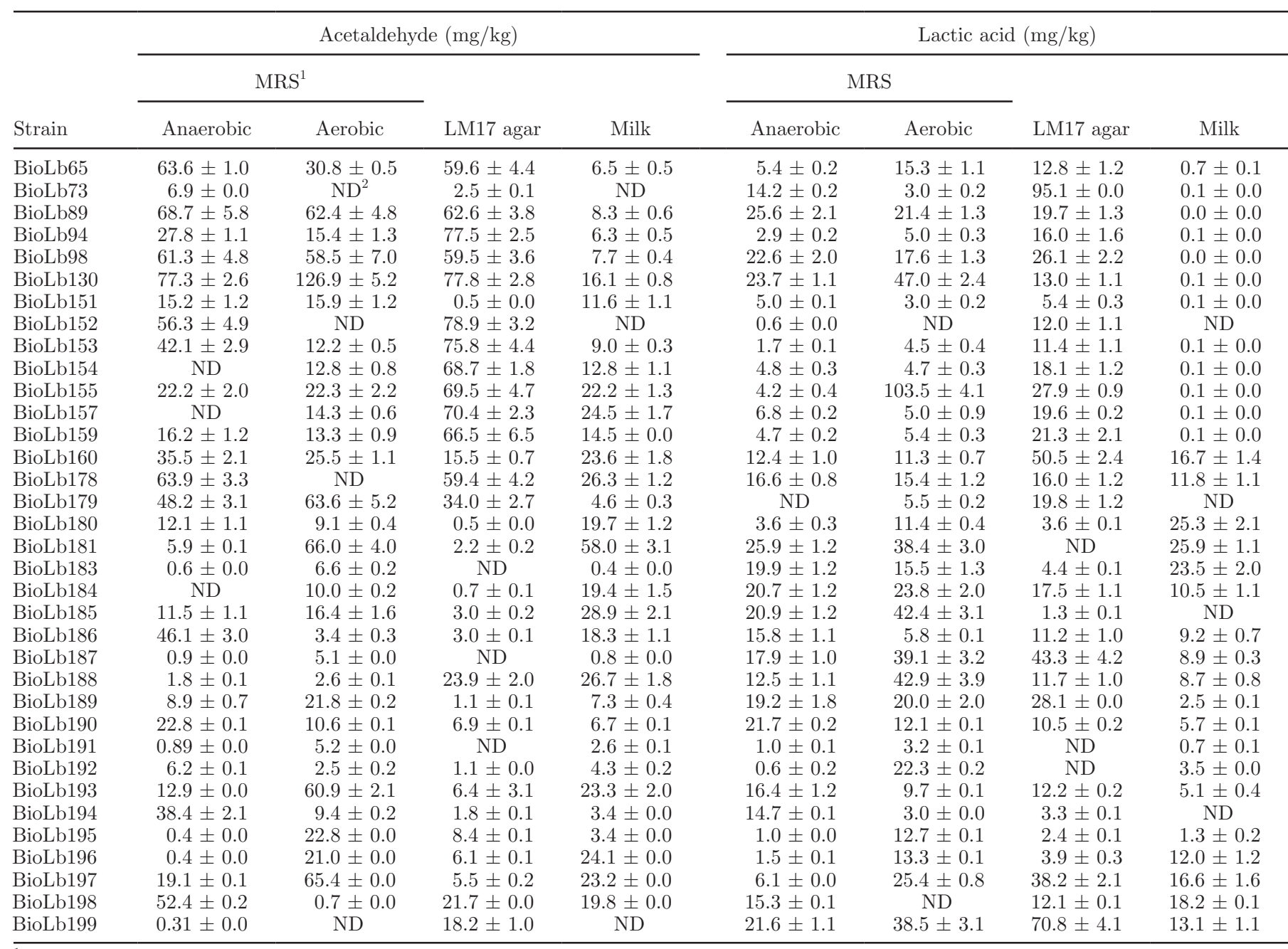

${ }^{1} \mathrm{MRS}=$ de Man, Rogosa, and Sharpe agar.

${ }^{2} \mathrm{ND}=$ not detectable.

Vries, 1988). Although this separation requires a chiral column that was not used in our experiments, the reference we used for the system enabled us to detect primarily the $\mathrm{L}(+)$ isomer. Because the influence of lactic acid on yogurt aroma is not only related to its total amount present in the fermented product but also to the ratio of the 2 isoforms $[\mathrm{D}(-)$ or $\mathrm{L}(+)]$ found in it, it was infeasible for us to constitute a direct relation between the measured amount of lactic acid and its contribution to the yogurt flavor.

Titratable acidity may have been measured to monitor $\mathrm{pH}$ change in the media studied. However, as it was discussed by Sherbon (1988), acidity of the media is dependable on various factors, such as the temperature and light conditions, the buffer system present in the media, and even the researcher who performs the task. Although electrometric determination of $\mathrm{pH}$ is consid- ered to be convenient for the routine analysis in the industry (Robinson and Tamime, 2007), lactic acid levels are used as international standards in determining the quality of yogurt (IDF, 1992). As a result, we found it more suitable for our purpose, which is to investigate the potential use of the natural isolates in yogurt production, to measure lactic acid levels as milligrams per kilogram of media instead of $\mathrm{pH}$ monitoring.

In our study, it was observed that the production of the metabolites varied not only among the species but also among the strains of the same species. Considering the fact that the strains were isolated from different regions of Turkey, with varying environmental factors, such as temperature, humidity, and the milk content due to the diet on which the animals are fed, it is expected to see such a difference because it was demonstrated that dairy environment affected the ex- 
pression of the genes that were important in metabolic, physiological, and functional roles in LAB (Klaenhammer et al., 2007).

Despite the fact that each wild strain was unique in its potential to generate the metabolite of interest, the strains of $L$. bulgaricus were, in general, better at forming both metabolites. Besides, when anaerobic and aerobic conditions were compared, it was found that all isolates showed the best performance when they were grown in aerobic conditions. Oxygen presence seemed to be especially important for acetaldehyde production by both species for the lowest values of both species were determined in anaerobic conditions. As far as the media are concerned, L. bulgaricus was at its best to produce both metabolites when grown in its most suitable mixture (aerobic MRS). Streptococcus thermophilus, on the other hand, produced the highest lactic acid in its special media (aerobic SM17), whereas it generated the maximum acetaldehyde in LM17, a common media used for both species.

In addition to flavor, texture is one of the most essential components of yogurt quality. The characteristic texture of yogurt is mainly generated by the coagulation of the milk in which the starters were incubated. Although the evaluation of the texture was not in the scope of this study, it is worth noting that all strains examined were able to coagulate the milk, indicating a possible potential to contribute to the desired sensory properties.

Overall, the observation that only a few of the strains isolated from traditional yogurts, which are generally highly flavored, showed the ability to produce the most important flavor components in sufficient amounts agrees with the literature indicating that combining the 2 species in a starter culture synergistically affects the taste of yogurt compared with situations where a single culture system is used (Georgala et al., 1995). Accordingly, it is coherent to expect that the total amount of the metabolites to be produced when these strains are combined may be different from the simple sum of the amounts produced by each strain separately. Bearing in mind that lactose is used as the starting material in both acetaldehyde and lactic acid production in the cells and that each species has a unique ability to metabolize it, it seems inevitable that the species will compete for lactose, and therefore the actual values for each metabolite will be deviated from any simple mathematical prediction. Herewith, it is also reasonable to suggest that the best starter culture mix that could be composed by using the strains tested in this study can only be determined experimentally.

The results generated through the research constitute the first set of data regarding the investigation of the flavor-forming metabolites produced by the LAB strains isolated from homemade Turkish yogurts. Thus, our results provide an undeniable originality in terms of natural LAB strains identified in the literature. Additionally, discovering some characteristics of these natural isolates also bears the potential to be useful in industrial manufacture of yogurt with a certain quality.

\section{ACKNOWLEDGMENTS}

This work was funded by The Scientific and Technological Research Council of Turkey (Project No: 110 O 218).

\section{REFERENCES}

Adolfsson, O., S. N. Meydani, and R. M. Russell. 2004. Yogurt and gut function. Am. J. Clin. Nutr. 80:245-256.

Akyol, I., K. Serdaroglu, Y. Gezginc, K. S. Dayisoylu, M. S. Ekinci, and E. Ozkose. 2009. Redirection of pyruvate pathway of lactic acid bacteria to improve cheese quality. Food Biotechnol. 23:200213.

Ayad, E. H. E., A. Verheul, C. de Jong, J. T. M. Wouters, and G. Smit. 1999. Flavour forming abilities and amino acid requirements of Lactococcus lactis strains isolated from artisanal and non-dairy origin. Int. Dairy J. 9:725-735.

Ayad, E. H. E., A. Verheul, J. T. M. Wouters, and G. Smit. 2000. Application of wild starter cultures for flavour development in pilot plant cheese making. Int. Dairy J. 10:169-179.

Beshkova, D., E. Smiova, G. Frengova, and Z. Simov. 1998. Production of flavour compounds by yogurt starter cultures. J. Ind. Microbiol. Biotechnol. 20:180-186.

Bolotin, A., B. Quinquis, P. Renault, A. Sorokin, S. D. Ehrlich, S. Kulakauskas, A. Lapidus, E. Goltsman, M. Mazur, G. D. Pusch, M. Fonstein, R. Overbeek, N. Kyprides, B. Purnelle, D. Prozzi, K. Ngui, D. Masuy, F. Hancy, S. Burteau, M. Boutry, J. Delcour, A. Goffeau, and P. Hols. 2004. Complete sequence and comparative genome analysis of the dairy bacterium Streptococcus thermophilus. Nat. Biotechnol. 22:1554-1558.

Chaves, A. C. S. D., M. Fernandez, A. L. S. Lerayer, I. Mierau, M. Kleerebezem, and J. Hugenholtz. 2002. Metabolic engineering of acetaldehyde production by Streptococcus thermophilus. Appl. Environ. Microbiol. 68:5656-5662.

Cheng, H. F. 2010. Volatile flavor compounds in yogurt: A review. Crit. Rev. Food Sci. Nutr. 50:938-950.

De Man, J. C., M. Rogosa, and M. E. Sharpe. 1960. A medium for the cultivation of lactobacilli. J. Appl. Bacteriol. 23:130-135.

Delorme, C., C. Bartholini, M. Luraschi, N. Pons, V. Loux, M. Almeida, E. Guédon, J. F. Gibrat, and P. Renault. 2011. Complete genome sequence of the pigmented Streptococcus thermophilus strain JIM8232. J. Bacteriol. 193:5581-5582.

Georgala, A., K. Tsakalidou, E. Kandarakis, and G. Kalantzopoulos. 1995. Flavour production in ewe's milk and ewe's milk yogurt, by single strains and combinations of Streptococcus thermophilus and Lactobacillus delbrueckii subsp bulgaricus, isolated from traditional Greek yogurt. Lait 75:271-283.

Ginovart, M., D. Lopez, J. Valls, and M. Silbert. 2002. Simulation modelling of bacterial growth in yogurt. Int. J. Food Microbiol. $73: 415-425$.

Hao, P., H. Zheng, Y. Yu, G. Ding, W. Gu, S. Chen, Z. Yu, S. Ren, M. Oda, T. Konno, S. Wang, X. Li, Z. S. Ji, and G. Zhao. 2011. Complete sequencing and pan-genomic analysis of Lactobacillus delbrueckii ssp. bulgaricus reveal its genetic basis for industrial yogurt production. PLoS ONE 6:e15964.

Hofvendahl, K., and B. Hahn-Hägerdal. 2000. Factors affecting the fermentative lactic acid production from renewable resources. Enzyme Microb. Technol. 26:87-107. 
International Dairy Federation, Brussels (IDF). 1992. General Standard of Identity for Milk Products Obtained from Fermented Milks. Standard no. 163. Int. Dairy Fed., Brussels, Belgium.

Ito, Y., and T. Sasaki. 1994. Cloning and nucleotide sequencing of L-lactate dehydrogenase gene from Streptococcus thermophilus M-192. Biosci. Biotechnol. Biochem. 58:1569-1573.

Kabak, B., and A. D. W. Dobson. 2011. An introduction to the traditional fermented foods and beverages of Turkey. Crit. Rev. Food Sci. Nutr. 51:248-260.

Kao, Y. T., Y. S. Liu, and Y. T. Shyu. 2007. Identification of Lactobacillus spp. in probiotic products by real-time PCR and melting curve analysis. Food Res. Int. 40:71-79.

Klaenhammer, T. R., M. A. Azcarate-Peril, E. Altermann, and R. Barrangou. 2007. Influence of the dairy environment on gene expression and substrate utilization in lactic acid bacteria. J. Nutr. 137(Suppl. 2):748S-750S.

Magenis, R. B., E. S. Prudencio, R. D. M. C. Amboni, N. G. C. Junior R. V. B. Oliveira, V. Soldi, and H. D. Benedet. 2006. Compositional and physical properties of yogurts manufactured from milk and whey cheese concentrated by ultrafiltration. Int. J. Food Sci. Technol. 41:560-568.

Olieman, C., and E. S. de Vries. 1988. Determination of D- and L-lactic acid in fermented dairy products with HPLC. Neth. Milk Dairy J. $42: 111-120$.

Ozer, B., and F. Atasoy. 2002. Effect of addition of amino acids, treatment with beta-galactosidase and use of heat-shocked cultures on the acetaldehyde level in yogurt. Int. J. Dairy Technol. 55:166170 .

Panagiotidis, P., and C. Tzia. 2001. Effect of milk composition and heating on flavor and aroma of yogurt. Pages 160-167 in Food Flavors and Chemistry: Advances of the New Millennium. Royal Soc. Chem., Cambridge, UK.

Pastink, M. I., S. Sieuwertsa, F. A. M. de Bok, P. W. M. Janssen, B. Teusink, J. E. T. van Hylckama Vlieg, and J. Hugenholtza.
2008. Genomics and high-throughput screening approaches for optimal flavour production in dairy fermentation. Int. Dairy J. 18:781-789.

Routray, W., and H. N. Mishra. 2011. Scientific and technical aspects of yogurt aroma and taste: A review. Compr. Rev. Food Sci. Food Safe. 10:208-220.

Sherbon, J. W. 1988. Physical properties of milk. Pages 409-460 in Fundamentals of Dairy Chemistry. N. P. Wong, ed. Van Nostrand Reinhold, New York, NY.

Singh, J. 1983. Influence of heat treatment of milk and incubation temperature on S. thermophilus and L. acidophilus. Milchwissenschaft 38:347-348

Sun, Z., X. Chen, J. Wang, W. Zhao, Y. Shao, Z. Guo, X. Zhang, Z. Zhou, T. Sun, L. Wang, H. Meng, H. Zhang, and W. Chen. 2011. Complete genome sequence of Lactobacillus delbrueckii ssp. bulgaricus strain ND02. J. Bacteriol. 193:3426-3427.

Tabasco, R., T. Paarup, C. Janer, C. Pelaez, and T. Requena. 2007. Selective enumeration and identification of mixed cultures of Streptococcus thermophilus, Lactobacillus delbrueckii subsp bulgaricus, L. acidophilus, L. paracasei subsp paracasei and Bifidobacterium lactis in fermented milk. Int. Dairy J. 17:1107-1114.

Tamime, A. Y., and R. K. Robinson. 2007. Yogurt: Science and Technology. 3rd ed. Woodhead Publishing Limited, Abingdon, UK.

Terzaghi, B. E., and W. E. Sandine. 1975. Improved medium for lactic streptococci and their bacteriophages. Appl. Microbiol. 29:807813.

Zhang, Q. L., J. Y. Ren, H. F. Zhao, M. M. Zhao, J. Y. Xu, and Q. Z. Zhao. 2011. Influence of casein hydrolysates on the growth and lactic acid production of Lactobacillus delbrueckii ssp. bulgaricus and Streptococcus thermophilus. Int. J. Food Sci. Technol. 46:1014-1020. 